\title{
Removal of phenol from aqueous solution using polymer inclusion membrane based on mixture of CTA and CA
}

\author{
Nadjib Benosmane ${ }^{1,2} \cdot$ Baya Boutemeur ${ }^{2} \cdot$ Safouane M. Hamdi ${ }^{3}$ Maamar Hamdi ${ }^{2}$
}

Received: 26 December 2016 / Accepted: 8 November 2017 / Published online: 24 January 2018

(c) The Author(s) 2018. This article is an open access publication

\begin{abstract}
Nowadays, there are increasingly stringent regulations requiring more and more treatment of industrial effluents to generate product waters which could be easily reused or disposed of to the environment without any harmful effects. In the present work, the removal of phenol from aqueous solution across polymer inclusion membrane (PIM), based on mixture of cellulose triacetate and cellulose acetate as support (75/25\%), calix[4]resorcinarene derivative as a carrier and 2-nitrophenyl octyl ether (2-NPOE) as plasticizer was investigated. The experimental part of this investigation involved the influence of carrier nature, plasticizer concentration, $\mathrm{pH}$ phases, and phenol initial concentration on the removal efficiency of phenol from synthetic wastewater. A PIM containing $0.1 \mathrm{~g}$ (of mixture polymer), $(0.15 \mathrm{~g} / \mathrm{g}$ mixture of polymer) of carrier and $(0.03 \mathrm{ml} / \mathrm{g}$ mixture of polymer) of 2-NPOE provided the highest percentage of phenol removal efficiency over a 6-day transport; the removal was found to be about $95 \%$, indeed the removal was found to be highly dependent of $\mathrm{pH}$ phases. The feed solution in these transport experiments was at $\mathrm{pH} 2$, while the stripping solution contained $0.20 \mathrm{M} \mathrm{NaOH}$. This study claims that the PIM with a mixture of cellulose derivatives can be used effectively to remove phenols from wastewaters.
\end{abstract}

Keywords PIMs $\cdot$ Calix[4]resorcinarene $\cdot$ Cellulose derivatives $\cdot$ Wastewater treatment $\cdot$ Phenol removal

\section{Introduction}

Phenols discharged to aqueous systems can produce an unpleasant odor and are harmful to human health. Therefore, phenolic wastewater becomes a great concern in wastewater treatment. There are several techniques have been applied to remove the phenol and its derivatives from wastewater, including the conventional methods of distillation and extraction (Bendini et al. 2003) chemical oxidation (Amiri et al. 2011), biodegradation (Tobajas et al. 2012), and sorption (Hao et al. 2009). Of these methods, membrane separation appears to be a suitable process based on overall

Nadjib Benosmane

nadjibbenosmane@yahoo.fr

1 Department of Chemistry, Faculty of Sciences, University M'Hamed Bougara de Boumerdès (UMBB), Avenue de l'indépendance, 35000 Boumerdès, Algeria

2 Laboratoire de Chimie Organique Appliquée, Faculty of Chemistry, USTHB, BP 32 El-Alia, 16111 Algiers, Algeria

3 Clinical Biochemistry Department, CHU Toulouse, University of Toulouse, UPS, Toulouse, France separation performance. Studies on membrane separation of small organic molecules from dilute aqueous solutions have included systems based on bulk liquid membranes (Reis et al. 2007), emulsion liquid membranes (Manzak and Tutkun 2004), and supported liquid membranes (Badgujar and Rastogi 2011; Juang and Chen 1997). PIMs have attracted increasing interest due to their potential to reduce the chemical hazards associated with conventional solvent extraction technologies. In PIMs techniques, a complexant agent, the carrier is immobilized in a base polymer with a plasticizer. In recently conducted studies, we have verified the suitability of PIMs with Cyanex 923 as carrier and CTA as a base polymer to extract phenol from its dilute acidic solution and transport it quantitatively into receiving a solution containing at least $0.25 \mathrm{M}$ of $\mathrm{NaOH}$ (PérezSilva et al. 2013). The PIMs applied in these studies are relatively stable and provide the potential for a safe method for the removal of phenol from dilute aqueous solutions. The polymer inclusion membrane containing polyvinyl chloride (PVC) as the polymer matrix and $N, N$-di(1-methylheptyl) acetamide (N503) as a specific carrier was prepared by solvent evaporation and investigated in the facilitated transport of phenol from dilute aqueous solutions (Meng et al. 2015). 
In previous work (Benosmane et al. 2016), we have tested the transport of phenol through polymer inclusion membrane using triacetate cellulose (CTA) only as support and calix[4]resorcinarene as a carrier; in this study, we explored the potential of using polymer inclusion membrane (PIM) with the mixture of cellulose triacetate (CTA) and cellulose acetate (CA) as support and two calix [4]resorcinarenes as a carrier for phenol removal from synthetic wastewater. The removal efficiency characteristics of phenol from aqueous solutions were investigated through a batch study.

\section{Materials and methods}

\section{Membrane preparation}

Polymer inclusion membranes were prepared according to the procedure reported by Sugiura et al. (1987); the amount of each constituent was a function of the series of experiments to be performed. Thus, for CTA and CA membrane, $10 \mathrm{ml}$ of a polymer solution ( $0.1 \mathrm{~g}$ of mixture polymer CTA: $75 \%+$ CA: $25 \%$ in dichloromethane), calix[4]resorcinarene $(0-0.06 \mathrm{~g} / \mathrm{g}$ mixture of polymers) (Fig. 1), and plasticizer $(0-0.03 \mathrm{ml}$ of plasticizer/g mixture of polymers) were placed into a Petri dish of $9.0 \mathrm{~cm}$ diameter. This solution was allowed to evaporate overnight at room temperature in a hood.

\section{Phenol analyses}

The phenol quantification in the transport experiments was carried out using a UV/Vis spectrophotometer Jenway-Serie 6800 at $210 \mathrm{~nm}$.

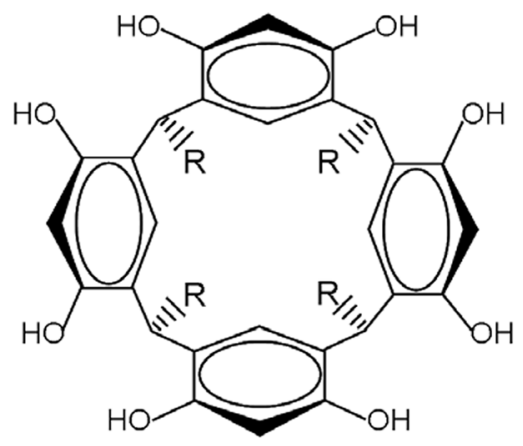

$$
\mathbf{R C 8}=-\mathrm{C}_{8} \mathrm{H}_{17} \quad \mathbf{R C p h}=
$$

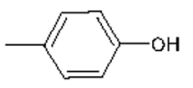

Fig. 1 Chemical structure of calix[4]resorcinarenes

\section{Transport experiments}

A typical laboratory scale device was used for phenol transport experiments through the PIM. It consisted of two compartments made of Teflon with a maximum capacity of $400 \mathrm{ml}$ separated by the PIM and the PIM area exposed to the aqueous phase were $12.56 \mathrm{~cm}^{2}$. One of them contained $10^{-3} \mathrm{M}$ of phenol as the feed phase, and the other, the stripping phase, contained $\mathrm{NaOH}$ in different concentrations. All transport experiments were carried out in triplicate keeping the aforementioned cell at room temperature $\left(25^{\circ} \mathrm{C}\right)$, both phases are agitated. In all figures, the reported error bars represent the standard deviation of the data.

\section{Results and discussion}

\section{Effect of contact time}

The effect of contact time on the efficiency removal of phenol is presented in Fig. 2. These figures show the removal of phenol increases with increasing contact time attains equilibrium in 4 days. Indeed the larger concentration gradient of phenol is driving force for phenol elimination across the PIM. After this period, the removal of phenol versus time curves are smooth and continue leading to saturation. The higher removal rate at initial period can be attributed to the increase of a number of vacant sites on the carrier in the PIM (Benosmane et al. 2009).

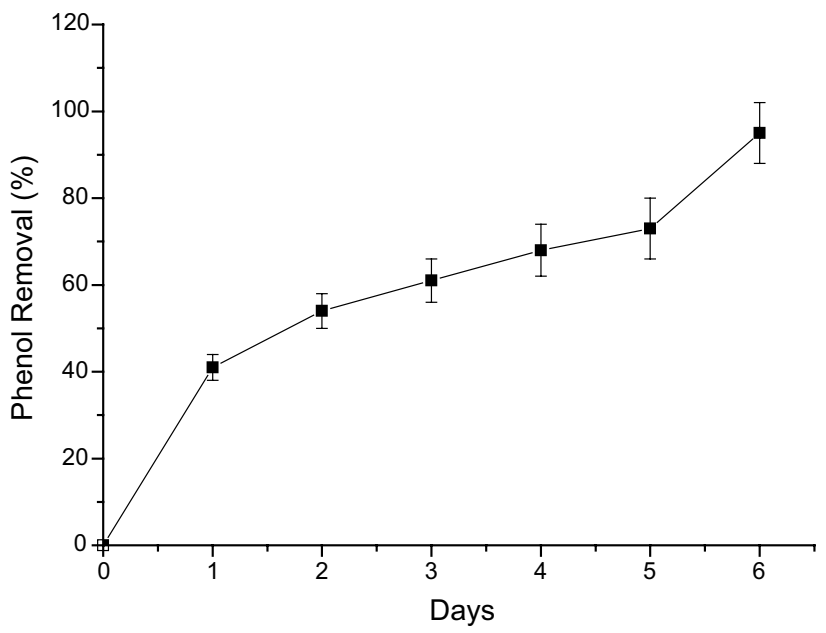

Fig. 2 Effect of contact time on removal of phenol. Transport conditions: feed phase: phenol $10^{-3} \mathrm{M}, \mathrm{pH} 2$. Stripping phase: $\mathrm{NaOH}$ $0.20 \mathrm{M}$. Membrane: $12.60 \mathrm{~cm}^{2}$ of surface area, calix[4]resorcinarene: $\mathrm{RC} 8$ ( $0.15 \mathrm{~g} / \mathrm{g}$ mixture of polymers), $0.03 \mathrm{ml}$ 2-NPOE/g polymers 
The quantity of phenol eliminated after 6 days of transport (95\%) was higher than 5 days (73\%) (Benosmane et al. 2016).

\section{Effect of stirring speed}

The effect of stirring speed of feed phase and stripping phase in case of phenol elimination using PIM was determined by varying the stirring speed from 200 to $800 \mathrm{rpm}$ (Fig. 3). It was observed that the transport of phenol increases from 200 to $600 \mathrm{rpm}$, but beyond $600 \mathrm{rpm}$ we revealed a decrease because the aqueous boundary layer thickness decreased continuously with increasing stirring speed up to $600 \mathrm{rpm}$. The increase of agitation speed beyond $600 \mathrm{rpm}$ leads to turbulence which then causes the release of the carrier out from membranes pores (Benosmane et al. 2015). Hence, the stirring speed of $600 \mathrm{rpm}$ was selected for further experiments.

\section{Effect of plasticizer (2-NPOE) contents on the transport of phenol}

Plasticizer plays a vital role in the transport of target as well as for membrane softness and flexibility in the PIMs. The influence of the plasticizer 2-NPOE content in the PIM on the removal of phenol was investigated by preparing PIMs at fixed quantity of calix[4]resorcinarene RC8 $(0.15 \mathrm{~g} / \mathrm{g})$ and plasticizer in varying amounts $(0-0.05 \mathrm{ml})$ (Fig. 4). PIM generated with the different amount of plasticizer was transparent with uniform thickness. Indeed, the transport test through the membrane without plasticizer and in the presence of carrier (RC8) shows a basal flux of phenol. Further variation in the amount of NPOE gives higher transport

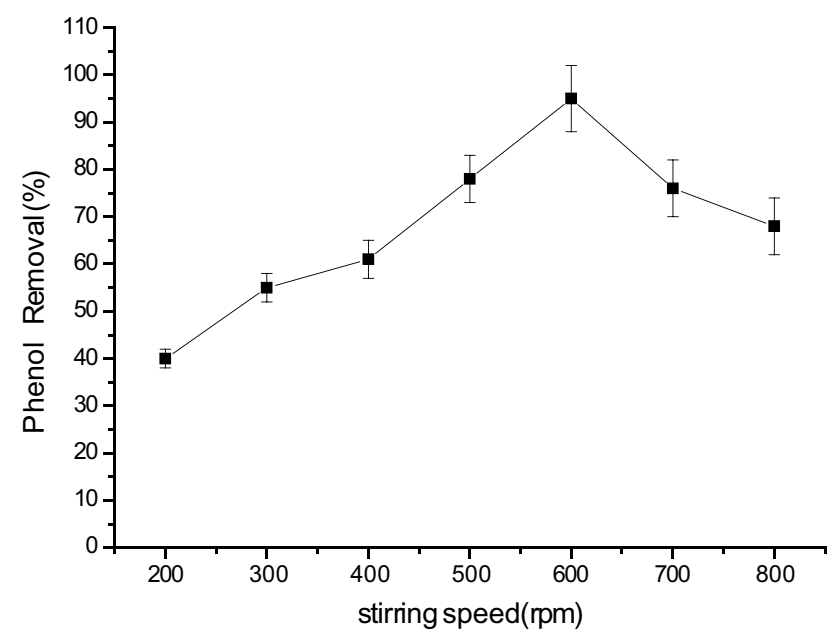

Fig. 3 Effect of stirring speed on removal of phenol. Transport conditions: feed phase: phenol $10^{-3} \mathrm{M}, \mathrm{pH}$ 2. Stripping phase: $\mathrm{NaOH}$ $0.20 \mathrm{M}$. Membrane: $12.60 \mathrm{~cm}^{2}$ of surface area, calix[4]resorcinarene: RC8 ( $0.15 \mathrm{~g} / \mathrm{g}$ mixture of polymers), $0.03 \mathrm{ml} 2-\mathrm{NPOE} / \mathrm{g}$ mixture of polymers values obtained after 6 days of transport

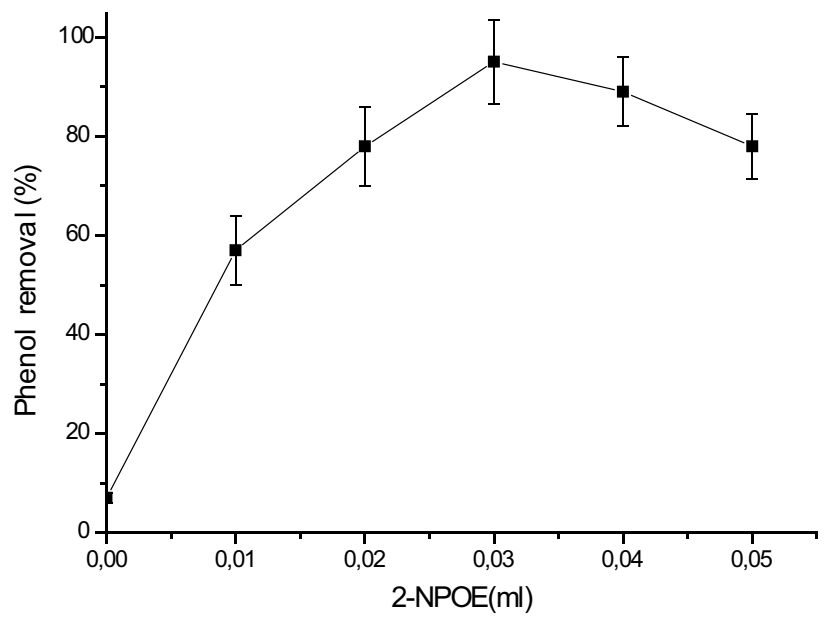

Fig. 4 Effect of plasticizer (2-NPOE) content on the transport of phenol. Transport conditions: feed phase: phenol $10^{-3} \mathrm{M}, \mathrm{pH} 2$. Stripping phase: $\mathrm{NaOH} 0.20 \mathrm{M}$. Membrane: $12.60 \mathrm{~cm}^{2}$ of surface area, calix[4] resorcinarene: RC8 (0.15 g/g mixture of polymers), $(0-0.05 \mathrm{ml}$ 2-NPOE/12.56 $\mathrm{cm}^{2}$ mixture of polymers) values obtained after 6 days of transport

efficiency up to $0.03 \mathrm{ml}$ of NPOE which might be due to the favorable plasticizer plasticization effect, beyond which a decrease in transport was attributed to intermolecular interaction between target and plasticizer molecule resulting in lower mass transfer (Nghiem et al. 2006).

\section{Effect of initial concentration of phenol}

The effect of initial phenol concentration in feed phase on the transport flux across the PIMs is presented in (Fig. 5).

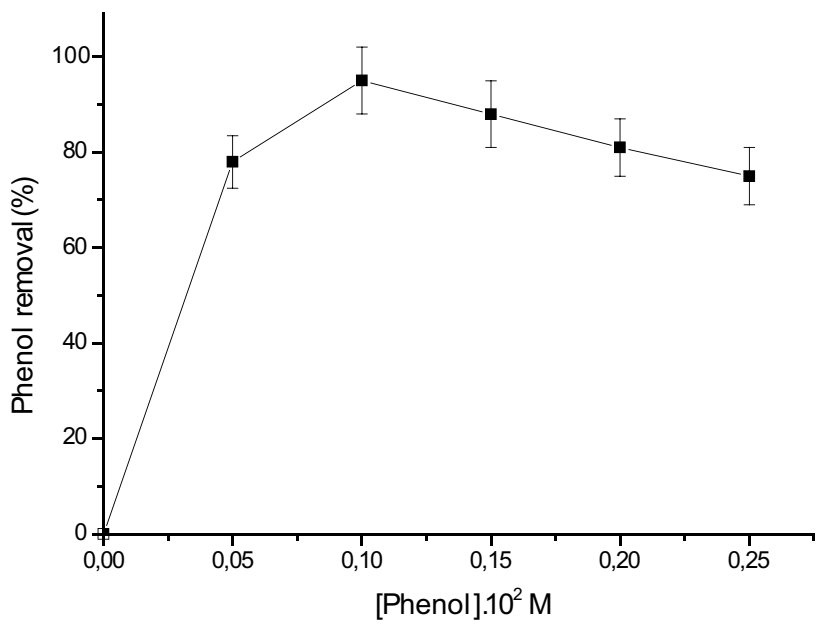

Fig. 5 Effect of initial concentration of phenol. Transport conditions: feed phase: phenol $(0-0.0025 \mathrm{M}), \mathrm{pH}$ 2. Stripping phase: $\mathrm{NaOH}$ $0.20 \mathrm{M}$. Membrane: $12.60 \mathrm{~cm}^{2}$ of surface area, calix[4]resorcinarene: RC8 $\left(0.15 \mathrm{~g} / \mathrm{g}\right.$ mixture of polymers), $\left(0.03 \mathrm{ml} 2-\mathrm{NPOE} / 12.56 \mathrm{~cm}^{2}\right.$ mixture of polymers) values obtained after 6 days of transport 
The quantity of target transported increases with increasing initial phenol concentrations in feed phase from 0 to $0.001 \mathrm{M}$, beyond a decrease in transported quantity was observed due to the formation of a milky layer on the membrane surface. This observation was likely one of the reasons of the flux limit. However, other reasons could be related to the kinetics of the phenol uptake, which could have reached its maximum value, or to a complex of different stoichiometries formed at the highest phenol concentration less soluble in the PIM core.

\section{Effect of calix[4]resorcinarene nature}

Some of the calix[4]resorcinarene have the ability to form a complex with phenolic compounds. In the present study, two different types of calix[4]resorcinarene such as RC8 and $\mathrm{RCph}$ were used as a carrier in polymer inclusion membrane (PIM). The phenol concentration was kept at $10^{-3} \mathrm{M}$. The membrane without calix[4]resorcinarene did not transport the phenol to the stripping phase. The percentage of phenol removal are presented in Table 1, which indicates that the RC8 shows higher mass transfer as compared to $\mathrm{RCph}$; which is dependent on the intermolecular interactions between the phenol and calix[4]resorcinarene; this complex can form by hydrogen bonding and or intermolecular interactions, when the complex formed is more stable and the phenol can be easily eliminated.

\section{Effect of $\mathrm{pH}$ solution of feed phase on the removal efficiency of phenol}

It can be observed in Table 2 . When the feed solution $\mathrm{pH}$ is equal to 2, the removal efficiency of phenol reaches the maximum 95\%; this result is in agreement with those obtained by Pérez-Silva et al. (2013) and Benosmane et al. (2016). The phenol-calix[4]resorcinarene complex was formed by hydrogen bond, in addition the degree of ionization of phenol was comparatively stronger at the higher $\mathrm{pH}(\mathrm{pH} 3)$ which decreases the complexation rate between calix[4]resorcinarene and phenol. The formation rate of phenol-calix[4]resorcinarene complex was influenced strongly by $\mathrm{pH}$ of feed phase. Regarding the influence of $\mathrm{pH}$ on the surface of the

Table 1 Effect of Calix[4]resorcinarene nature on removal of phenol

\begin{tabular}{ll}
\hline Calix[4]resorcinarene & Phenol removal (\%) \\
\hline RC8 & $95.05(6.87)$ \\
RCph & $81.65(5.34)$ \\
\hline
\end{tabular}

Transport conditions: feed phase: phenol $10^{-3} \mathrm{M}$, pH 2. Stripping phase: $\mathrm{NaOH} 0.20 \mathrm{M}$. Membrane: $12.60 \mathrm{~cm}^{2}$ of surface area, Calix[4] resorcinarene $0.15 \mathrm{~g} / \mathrm{g}$ mixture of polymers, $0.03 \mathrm{ml}$ (2-NPOE)/g mixture of polymers. Values obtained after 6 days of experimentation. \% RSD in parentheses
Table 2 Effect of $\mathrm{pH}$ solution of feed phase on the removal efficiency of phenol

\begin{tabular}{lll}
\hline $\begin{array}{l}\mathrm{pH} \text { in feed } \\
\text { phase }\end{array}$ & $\begin{array}{l}\text { Concentration of } \mathrm{NaOH} \text { in } \\
\text { strip phase }(\mathrm{M})\end{array}$ & Phenol removal (\%) \\
\hline 2 & 0.20 & $95.06(7.65)$ \\
4 & 0.20 & $70.65(6.54)$ \\
6 & 0.20 & $58.98(6.34)$ \\
8 & 0.20 & $41.76(5.97)$ \\
10 & 0.20 & $36.76(4.28)$ \\
12 & 0.20 & $21.65(4.78)$ \\
\hline
\end{tabular}

Transport conditions: feed phase: phenol $10^{-3} \mathrm{M}$, pH 2-12. Stripping phase: $\mathrm{NaOH} 0.20 \mathrm{M}$. Membrane: $12.60 \mathrm{~cm}^{2}$ of surface area, Calix[4] resorcinarene $(0.15 \mathrm{~g} / \mathrm{g}$ mixture of polymers $), 0.03 \mathrm{ml} \mathrm{2-NPOE} / \mathrm{g}$ mixture of polymers. Values obtained after 6 days of experimentation. \% RSD in parentheses

membrane when in contact with the environment medium, the surface of the membrane consists of cellulose acetate polymer chains and calix[4]resorcinarene macromolecules; in fact, the acid medium will not affect the surface by which this type of polymer is stable to $\mathrm{pH}$ acid and even see basic. We have verified with Infra-Red spectroscopy technique (FTIR) that the membranes after contact with the acidic medium we conclude no modification on the surface weres observed.

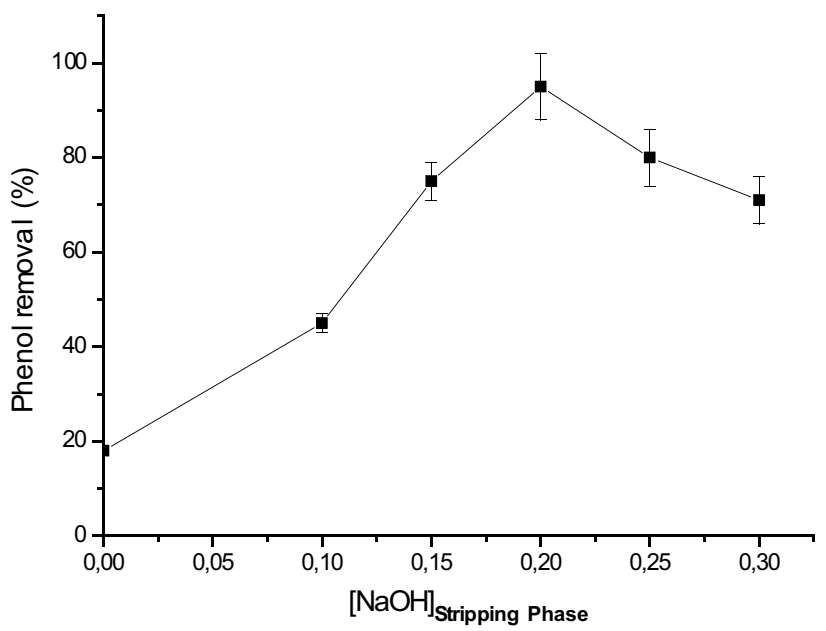

Fig. 6 Effect of $\mathrm{NaOH}$ concentration in stripping phase on the removal efficiency of phenol. Transport conditions: feed phase: phenol $10^{-3} \mathrm{M}, \mathrm{pH}$ 2. Stripping phase: $\mathrm{NaOH} 0-0.30 \mathrm{M}$. Membrane: $12.60 \mathrm{~cm}^{2}$ of surface area, calix[4]resorcinarene: RC8 $(0.15 \mathrm{~g} / \mathrm{g}$ mixture of polymers), $0.03 \mathrm{ml} 2-\mathrm{NPOE} / \mathrm{g}$ polymers. Values obtained after 6 days of transport 


\section{Effect of $\mathrm{NaOH}$ concentration in stripping phase on the transport of phenol}

Figure 6 shows the effect of $\mathrm{NaOH}$ concentration in strip phase on the elimination efficiency of phenol with keeping the $\mathrm{pH}$ of feed phase constant at $\mathrm{pH} 2$. We have observed that the removal of phenol increased with increasing the concentration of $\mathrm{NaOH}$ from 0 to $0.20 \mathrm{M}$ but with CTA used only as support, $\mathrm{NaOH}$ concentration was $0.25 \mathrm{M}$ (Benosmane et al. 2016); possible explanation was the change of character of surface in the case of the mixture of CTA and CA. At acidic medium, the mass transfer of target is less due to the presence of protons ions, which can prevent the complex formation between phenol and carrier. Moreover, the presence of $\mathrm{OH}^{-}$with high quantity can affect the formation of the complex.

\section{Effect of plasticizer content on membrane stability}

The stability of PIMs for a different quantity of plasticizer 2-NPOE (0.01-0.03 $\mathrm{ml})$ in PIMs preparation under the same conditions was evaluated. The feed and strip phases were renewed every 6 days (one cycle) without changing the membrane (Fig. 7.) A gradual decrease of the phenol removal efficiency was observed with increasing the number of cycles. We observed that in the case of the PIM with $0.01 \mathrm{ml}$ of plasticizer after 4 days of use the decrease was important with $47 \%$, but with $0.02 \mathrm{ml}$ of plasticizer the decrease appears to be linear and the percentage of diminution was $21 \%$; then with $0.03 \mathrm{ml}$ of NPOE, the decrease was reached $27 \%$.



Fig. 7 Effect of plasticizer content on membrane stability. Transport conditions: feed phase: phenol $10^{-3} \mathrm{M}, \mathrm{pH} 2$. Stripping phase: $\mathrm{NaOH}$ $0.20 \mathrm{M}$. Membrane: $12.60 \mathrm{~cm}^{2}$ of surface area, calix[4]resorcinarene: RC8 (0.15 g/g mixture of polymers), 2-NPOE $(0.01-0.03 \mathrm{ml}) / \mathrm{g}$ mixture of polymers

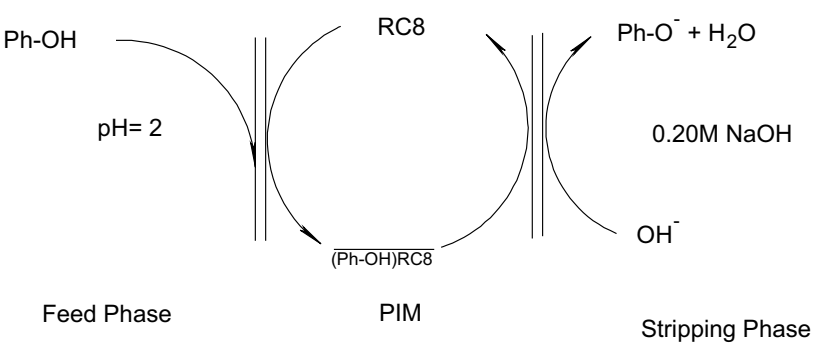

Fig. 8 Mechanism scheme for the transport of phenol from acidic aqueous solution to alkaline stripping phase using PIM with calix[4] resorcinarene $(\mathrm{RC} 8)$

\section{Suggested mechanism}

Transport of phenol by the calix[4]resorcinarene RC 8 obeys a facilitated co-transport (Fig. 8). As it is shown in Fig. 8, the phenol forms a neutral complex at the interface feed phase/membrane and after forming a hydrophobic pair complex, the resulting complex diffuses through the membrane phase to the membrane/strip phase interface. Then the free carrier diffuses back across the polymer inclusion membrane and the cycle starts again. The net result is the mass transfer of phenol forms source phase to the receiving phase through a PIM system.

\section{Conclusion}

In the present study, two different types of calix[4]resorcinarene such as RC8 and RCph were used as a carrier in polymer inclusion membrane (PIM). RC8 shows higher mass transfer as compared to RCph; which is dependent on the intermolecular interactions between the phenol and calix[4]resorcinarene, this complex can be formed by hydrogen bonding and/or intermolecular interactions. It can be observed when the feed solution $\mathrm{pH}$ is equal to 2 , the removal efficiency of phenol reaches the maximum $95 \%$, since the larger concentration gradient of phenol is the factor driving phenol across the PIM. This work has demonstrated the developed PIM on the removal of phenol from synthetic wastewater. The method was simple, easy and also rapidly applied for wastewater sample. The results show that the PIM with the mixture of CTA and CA has the high analytical potential for removing phenol from water samples.

Open Access This article is distributed under the terms of the Creative Commons Attribution 4.0 International License (http://creativecomm ons.org/licenses/by/4.0/), which permits unrestricted use, distribution, and reproduction in any medium, provided you give appropriate credit to the original author(s) and the source, provide a link to the Creative Commons license, and indicate if changes were made. 


\section{References}

Amiri H, Jaafarzadeh N, Ahmadi M, Martinez SS (2011) Application of LECA modified with Fenton in arsenite and arsenate removal as an adsorbent. Desalination 272:212-217

Badgujar V, Rastogi NK (2011) Extraction of phenol from aqueous effluent using triglycerides in supported liquid membrane. Desalination Water Treat 36:187-196

Bendini A, Cerretani Bonoli M, Biguzzi L, Lercker B, Toschi TG (2003) Liquid-liquid and solid-phase extraction of phenols from virgin olive oil and their separation by chromatographic and electrophoretic methods. J Chromatogr A 985:425-433

Benosmane N, Boutemeur B, Hamdi M, Hamdi SM (2009) Selective transport of metal ions across polymer inclusion membranes (PIMs) containing calix[4]resorcinarenes. Sep Purif Technol 65:211-219

Benosmane N, Boutemeur B, Hamdi M, Hamdi SM (2015) Application of cellulose acetate membranes for removal of toxic metal ions from aqueous solution. Fresenius Environ Bull 24:2296-2309

Benosmane N, Boutemeur B, Hamdi SM, Hamdi M (2016) The removal of phenol from synthetic wastewater using calix[4]resorcinarene derivative based polymer inclusion membrane. Algerian J Environ Sci Technol 2(2):26-33

Hao X, Pritzker M, Feng X (2009) Use of pervaporation for the separation of phenol from dilute aqueous solutions. J Membr Sci 335(1):96-102

Juang RS, Chen LJ (1997) Transport rate of citric acid across a supported liquid membrane containing salts of a tertiary amine. J Membr Sci 123:81-87
Manzak A, Tutkun O (2004) Extraction of citric acid through an emulsion liquid membrane containing aliquat 336 as a carrier. Sep Sci Technol 39:2497-2512

Meng X, Gao CG, Wang L, Wang X, Tang W, Chen H (2015) Transport of phenol through polymer inclusion membrane with $N, N$-di (1-methylheptyl) acetamide as carriers from aqueous solution. $\mathbf{J}$ Membr Sci 493:615-621

Nghiem LD, Morname P, Potter JM, Perera Cattrall RW, Kolev SD (2006) Extraction and transport of metal ions and small organic compounds using polymer inclusion membranes (PIMs). J Membr Sci 218:7-41

Pérez-Silva I, Galán-Vidal CA, Ramírez-Silva MT, Rodríguez JA, Álvarez-Romero GA, Páez-Hernández ME (2013) Phenol removal process development from synthetic wastewater solutions using a polymer inclusion membrane. Ind Eng Chem Res 52:4919-4923

Reis MTA, Ondina MF, Rosinda M, Ismael C, Jorge M, Carvalho R (2007) Recovery of phenol from aqueous solution using liquid membranes with Cyanex 923. J Membr Sci 305:313-324

Sugiura M, Kawa MK, Urita S (1987) Effect of plasticizer on the carrier-mediated transport of zinc ion through cellulose triacetate membranes. Sep Sci Technol 22:2263

Tobajas M, Mohedano AF, Rodriguez JJ (2012) Enhancement of cometabolic biodegradation of 4-chlorophenol induced with phenol and glucose as carbon sources. J Environ Manag 95:116-121

Publisher's Note Springer Nature remains neutral with regard to jurisdictional claims in published maps and institutional affiliations. 